\title{
Structural and composition irregularities in GaAs:Si/GaAs films grown by liquid-phase epitaxy
}

\author{
V.P. Klad'ko, L.I. Datsenko, Z.V. Maksimenko, O.S. Lytvyn, I.V. Prokopenko, Z. Żytkiewicz ${ }^{1)}$ \\ Institute of Semiconductor Physics NAS of Ukraine, Kyiv, Ukraine \\ 1) Institute of Physics PAN, Warsaw, Poland
}

\begin{abstract}
Stoichiometry parameters as well as the microdefects ones for GaAs:Si/GaAs thin films grown by liquid-phase epitaxy were investigated by means of method of X-ray integrated reflectivity energy dependencies analysis for quasiforbidden reflections (200) in the interval of wavelengths near absorption K-edges of GaAs components.
\end{abstract}

Keywords: X-ray, absorption K-edge, GaAs, stoichiometry, structure parameters, quasiforbidden reflections.

Paper received 14.04.00; revised manuscript received 24.05.00; accepted for publication 06.06.00.

\section{Introduction}

One of the most important problems in semiconductor materials investigations is an examination of point defects and stoichiometry. These defects determine electrical and optical properties, efficiency and reliability of devices created on the basis of these materials [1-5]. The important moment in this problem is determination of localization and concentration of electrically active impurities and native atoms in a lattice.

Experimental methods of point defects investigation such as electrical (Hall's effect) and optical (photoluminescence) ones are indirect, and localization of defects in a lattice can not be determined. For this purpose, the considerable attention of researchers is recently given to X-ray diffraction methods. Despite an integral character of these methods (each type of separate defects can not be determined as it could be done in spectroscopic methods) the analysis of diffraction peaks intensity is a direct method that allows obviously to illustrate localization of such defects in lattice, as well as deformation fields around them. Methods of stoichiometry determination and point defects characterization have been described in detail [6-11]. Particularly in [6], the influence of silicon high doping level $\left(\sim 10^{20} \mathrm{~cm}^{-3}\right)$ of GaAs films obtained by MBE and LPE methods on their structural characteristics and localization of impurity atoms in a lattice was analyzed. However, the process of stoichiometry determination was carried out without the common structure analysis often used for studying epitaxial layer defects (estimation of dislocation density, concentration of microdefects, etc.) The so-called kinematic approach of X-ray diffraction theory was used in this work. At the same time, as was shown in [8], these defects can influence on precision of stoichiometry determination. Besides, they influence on material components and impurity atoms distribution in crystals. The silicon doped epitaxial structures obtained by the LPE method on GaAs are used for some types of light-emitting diodes, therefore examination of their structure is an actual problem.

The aim of this work is to study characteristics of microdefects and stoichiometry of GaAs:Si/GaAs films as well as to ascertain possible connection of these parameters with data of electrical and SIMS measurements. For this purpose, the analysis of energy dependencies of integrated reflected power (reflectivity) (IR) for quasiforbidden reflections (QFR) near Ga and As absorption $\mathrm{K}$-edges (the dynamical approach of the X-ray diffraction theory was applied), IR measurements of characteristic $\mathrm{CuK}_{\alpha 1}$ - irradiation and deformation characteristics of epitaxial systems determination were carried out.

\section{Theoretical principles of stoichiometry determination methods}

The IR energy dependencies for real crystals GaAs in the interval of wavelengths near absorption K-edges of components $\lambda_{K}^{\mathrm{As}}<\lambda<\lambda_{K}^{\mathrm{Ga}}$ can be used for investigation of $\mathrm{X}$-ray dispersion character in dependence on the irradiation absorption level that is determined by parameter $\mu \cdot t(\mu$ is a normal coefficient of photoelectric absorption that varies with an X-ray wavelength, $\lambda$ ) for a fixed thickness of a crystal, $t$ [9]. Besides, it is possible to study both 


\section{V.P. Klad'ko et al.: Structural and composition irregularities in GaAs:Si/GaAs ...}

dependencies of crystal structural perfection parameters (Debye-Waller static factor, $L$, and coefficient of extinction, $\mu_{d s}$ ) from diffraction parameters (wavelength and vector of a diffraction $H$ ), and level of stoichiometry $\Delta=C_{\mathrm{Ga}}-C_{\mathrm{As}}$, where $C_{i}-$ atomic concentration of the lattice components $[8,9]$. The experiments were carried out in the Bragg geometry because of epitaxial films were chosen as objects of investigations.

In the case of QFR the changes in $\chi_{r h}$ and $\chi_{i h}$ ratio (where is a coefficient of the Fourier expansion of a crystal susceptibility real and imaginary parts, respectively) is specially appreciable just right near the $\mathrm{K}$ - absorption edges of lattice components $\lambda_{K}$.

The real part of this dynamic parameter changes very quickly for the wavelengths located between absorption edges due to an anomalous dispersion of X-rays, while the imaginary part is approximately stationary (Fig. 1). These changes lead to the specific point occurrence in the range of wavelengths $\lambda_{K}^{\mathrm{As}}<\lambda<\lambda_{K}^{\mathrm{Ga}}$, where the real part of $c$ that is sensible to changes in crystal stoichiometry is equal to zero. The theoretical analysis of dynamic theory equations for integrated intensity of a diffraction peak in a real crystals was carried out in [12], and allows to use an arbitrary relations between $\chi_{r h}$ and $\chi_{i h}$, including $\chi_{r h}=0$.

The coherent term of IR, $R_{c o h}(\Delta \vartheta)$, for the Bragg diffraction depends on a dynamic parameter $\left|\chi_{h} \cdot \chi_{\bar{h}}\right|=\left|\Psi_{h}\right|^{2} \cdot\left(1-\kappa_{0}^{2}+2 \cdot i \cdot p_{0}\right)$ in the case of QFR, where real part of the Fourier coefficient can be also equal to zero. Here, $\Psi_{h}^{2}=\left|\chi_{r h}\right|^{2}+\left|\chi_{i h}\right|^{2}$,

$$
\begin{aligned}
& \kappa_{0}=\sqrt{2} \cdot \frac{\left|\chi_{i h}\right|}{\left|\Psi_{h}\right|}, \\
& p_{0}=\left(\chi_{r h}^{\prime} \cdot \chi_{i h}^{\prime}+\chi_{r h}^{\prime \prime} \cdot \chi_{i h}^{\prime \prime}\right) / \Psi_{h}^{2},
\end{aligned}
$$

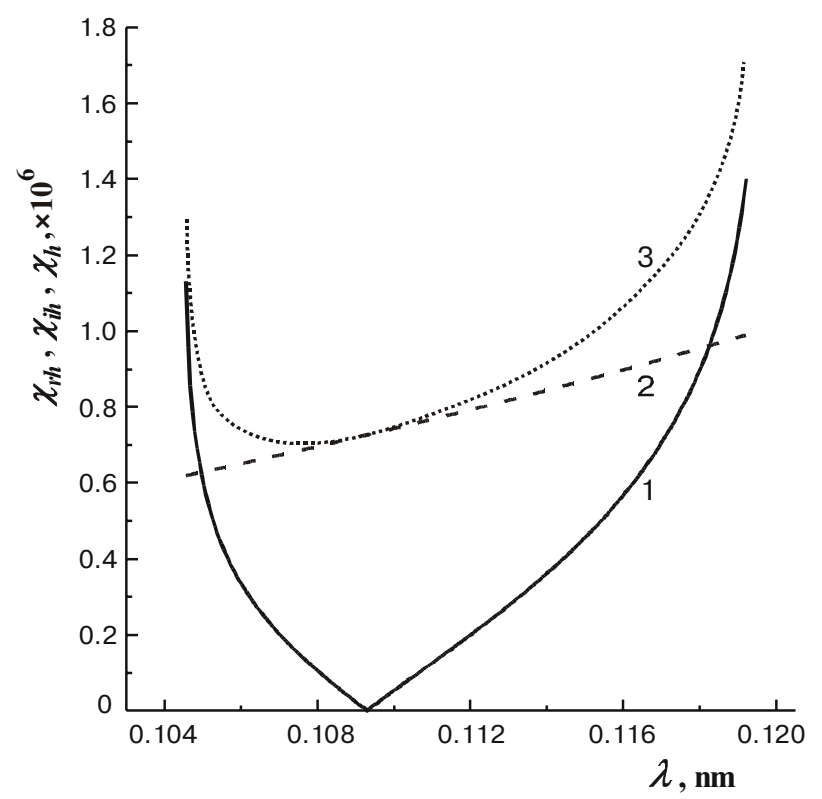

Fig. 1. Energy dependencies of real (1) and imaginary (2) parts of the Fourier expansion of a crystal susceptibility (3) for QFR (200).
The $R_{c o h}(\Delta \vartheta)$ does not depend on thickness for a centrosymmetric semi-infinite perfect crystal :

$R_{c o h}(\Delta \vartheta)=\zeta \cdot\left(L-\sqrt{L^{2}-1}\right)$,

where

$L=\frac{z^{2}+g_{0}^{2}+\left[\left(z^{2}+\kappa_{0}^{2}-g_{0}^{2}-1\right)^{2}+4 \cdot\left(z \cdot g_{0}-p_{0}\right)^{2}\right]^{1 / 2}}{\left[\left(1-\kappa_{0}^{2}\right)^{2}+4 \cdot p_{0}^{2}\right]^{1 / 2}}$,

$g_{0}=-\left|\chi_{i 0}\right| \cdot \frac{\sqrt{b}+1 / \sqrt{b}}{2 \cdot C \cdot \Psi_{h}}, b=\gamma_{0} /\left|\gamma_{h}\right|, \zeta=\sqrt{\frac{1+2 \cdot s_{0}}{1-2 \cdot s_{0}}}$,

$s_{0}=\left(\chi_{r h}^{\prime \prime} \cdot \chi_{i h}^{\prime}-\chi_{r h}^{\prime} \cdot \chi_{i h}^{\prime \prime}\right) / \Psi_{h}^{2}$, and $z=\frac{\Delta \vartheta \cdot \sin 2 \vartheta}{C \cdot \Psi_{h}} \cdot \sqrt{b}$.

In these symbols $D J$ is angular deviation of a wave vector of an incident wave from the precise Bragg direction, $\gamma_{0}$ and $\gamma_{h}$ are cosines of angles between an interior normal to input surface of a crystal and wave vectors of incident and scattered waves.

As known, in an real crystal, except for coherent term $R_{c o h}(\Delta \vartheta)$, there is a diffuse term $R_{i d}$. The above mentioned equations (1), (2) could be extended, in accordance with $[10,11]$, to a case of a real crystal by replacement of $\chi_{h}$ with $\Psi_{h} \cdot \exp (-L)$ and $\chi_{i 0}$ with $\left(\left|\chi_{i 0}\right|+\mu_{d s} / K\right)$. Here, $\mu_{d s}$ is the coefficient of additional losses of energy due to diffuse scattering on defects, $K=2 \cdot \pi / \lambda$. In this way, it is possible to receive the equation for coherent term of scattering in crystalline medium with Coulomb defects $[10,11]$, which the impurity clusters belong to. Then $g=g_{0} \cdot\left(1+\mu_{d s} \cdot C^{2} / \mu_{0}\right) \cdot \exp (L)$, and $\bar{R}_{c o h}=R_{c o h} \cdot E$, $E=\exp (-L)$.

The diffuse term of crystal reflectivity with homogeneously distributed defects, integrated on output angles, can be defined as [11]:

$R_{D}(\Delta \vartheta)=F_{d i n}(\Delta \vartheta) \cdot \frac{\mu_{d s}\left(k_{0}\right) \cdot \gamma_{0}}{2 \cdot \mu_{i}(\Delta \vartheta)}$,

where $R_{D}(\Delta \vartheta)$ is the function both of Coulomb defect concentrations and sizes as well as scattering parameters and deformation characteristics of a crystal.

The IR of coherent and diffuse terms for experimental values of $R_{I}^{\exp }$ were determined by intensity integration on angular variable $\Delta \vartheta$. Thus, the above mentioned equations (1) - (3) allows to quantitatively describe the behavior of total IR in a wide angular range for Coulomb defects with arbitrary sizes and concentrations too. The expression for total IR of a real crystal could be written as the sum of coherent and diffuse terms:

$R_{I}=R_{c o h}+R_{i D}$,

The energy dependencies $R_{I}(\lambda)$ were calculated accordingly to equation (4) where equations (2) and (3) as 


\section{V.P. Klad'ko et al.: Structural and composition irregularities in GaAs:Si/GaAs ...}

well as dependence of scattering parameters from wavelength and dispersion corrections were taken into account.

The structural perfection parameters $L$ and $\mu_{D S}(\lambda)$ of epitaxial layers GaAs:Si/GaAs were determined by computer simulation adjustment of theoretical dependence (4) to experimental values. During adjustment the known fact from [13] was used, that extinction parameter is proportional not only to but to the Fourier coefficient of a crystal susceptibility $\chi_{h}\left(\mu_{d s} \sim\left(\chi_{h} \cdot \lambda\right)^{2}\right)$, too. As it was noted above, for QFR in the range of wavelengths $\lambda_{K}^{\mathrm{As}}<\lambda<\lambda_{K}^{\mathrm{Ga}}$ there exist a section, where the structure factor $F_{r h}$, and consequently $\chi_{r h}$, is equal to zero due to influence of Honel real dispersion corrections $f$ for atomic formfactors $f_{0}$ of crystal matrix components. As one could see from Fig. 1, the changes in concentration $c_{i}$ relationships of crystal matrix components lead to changes of a point $F_{r h}=0$ position on the energy dependence $R(\lambda)$. This fact is the basis of experimental method for stoichiometry degree control of a real crystals, which was used in the present paper. Thus, from energy dependencies $R(\lambda)$ of QFR for wavelengths located between K-absorption edges of $\mathrm{Ga}$ and $\mathrm{As}$, it is possible to receive values of structural perfection parameters and $\Delta=\left(C_{\mathrm{Ga}}-C_{\mathrm{As}}\right) / C_{\mathrm{As}}$ in the case when the epitaxial film contains structural defects.

\section{Experimental technique and samples}

Measurements of integrated intensities (II) for (200) and (400) diffraction peaks, as functions of wavelengths of Xray inverse brensstrahlung spectra were carried out using a one-crystal spectrometer (OCS). The facility operation mode allowed to avoid influence of multiple harmonics $n \cdot \lambda / 2$. The geometrical scheme of the experiment (slit width $S=50 \mu \mathrm{m}$ and its distance from a sample $x=160 \mathrm{~mm}$ ) allowed to reach energy resolution of OCS about $40 \mathrm{eV}$ $(\Delta l=0.005 \AA)$. Intensity measurements of an incident on an explored crystal radiation $I_{0}$ with a wavelength $\lambda$ was carried out using a reference (standard) dislocation-free crystal of silicon (reflection (220)). Measured in this manner values $I_{0}(\lambda)$ for wavelength of X-ray inverse brensstrahlung spectrum were used for IR determination $R_{I}(\lambda)$ of investigated GaAs epitaxial films. The cumulation of pulses number was carried out for 40-300 $\mathrm{s}$ in each point (number of points was about 300 ) for improvement of II measurement precision $(\sim 1 \%)$. Influence of background scattering was taken into account in accordance with [14]. The dynamic parameters of scattering $\chi_{h}$, $\chi_{i 0}$ that influence on IR, were simulated using equations from [15]. The oscillator forces at Honle correction calculations and temperature factors were taken into account at $\chi_{h}, \chi_{i 0}$ simulations accordingly to $[16,17]$. The parameters of structural perfection were determined by computer fitting of theoretical dependence $R_{I}^{T}(\lambda)$ for reflections (200) and (400) to experimental values IR $R_{I}^{\exp }(\lambda)$ by the method described in [18]. The aim of such fitting was minimization of the following functional:
$\Phi=\sum_{i=1}^{N}\left(R_{I}^{\exp }(\lambda)_{i}-R_{I}^{T}(\lambda)_{i}\right)^{2} / \sigma_{i}^{2}$,

where $\sigma_{i}^{2}$ is a statistical error of calculation. The number of iterations during this fitting procedure was chosen enough to reach the precision of the order of $2-3 \%$.

The integrated intensities of characteristic $\mathrm{CuK}_{a 1}$-irradiation for reflections (200), (400) and (600) as well as elastic strains in epitaxial layers [19] were measured using double crystal spectrometer (DCS).

The GaAs:Si/GaAs epitaxial films were chosen for investigation. Films were grown by LPE method. Their basic parameters are given in Table 1. The films were thick enough to explore only their structure without substrate contribution in the necessary tanges of wavelengths. The concentration of silicon atoms $N_{\mathrm{Si}}$ in GaAs films was determined by SIMS method. The measurements of basic electrophysical parameters (carriers concentration, mobility) were carried out using standard methods [20].

\section{Results and discussions}

The silicon is an element of IV group of Periodical Table and in semiconductors $\mathrm{A}^{3} \mathrm{~B}^{5}$ can play a role of both donor and acceptor, which depends on a site in the lattice. The substitution of Ga or As atoms with silicon in a crystal lattice leads to changes of effective concentration of components and structure factor $F_{h}$ value, which is described by equation (6):

$$
\begin{aligned}
& F_{h}=4 \cdot\left\{\left(1-c_{\mathrm{Si}}\right) \cdot\left[\left(f_{0}+f^{\prime}\right)_{\mathrm{As}}+f_{\mathrm{As}}^{\prime \prime}\right]+\right. \\
& \left.+c_{\mathrm{Si}} \cdot\left(f_{0}+f^{\prime}\right)_{\mathrm{Si}}-c_{\mathrm{Ga}} \cdot\left[\left(f_{0}+f^{\prime}\right)_{\mathrm{Ga}}+f_{\mathrm{Ga}}^{\prime \prime}\right]\right\}
\end{aligned}
$$

This change leads to shift $\lambda^{\text {min }}-\lambda_{s}^{\text {min }}$ of a minimum location on energy dependence IR for QFR.

Experimental energy dependencies of IR is shown in the Fig. 2: $(1,2)$ for $(200)$ reflection in the range of wavelengths $\lambda_{K}^{\mathrm{As}}<\lambda<\lambda_{K}^{\mathrm{Ga}}$ for two samples №2 and №5 (points). The continuous curve in Fig. 2 shows the energy dependence of IR obtained by computer adjustment of parameters for real crystal. Positions of IR minima for experimental curves and curves for stoichiometric sample are shown in insertion of Fig. 2. The minima were determined by differentiation of adjusted curves of measured dependencies. As follows from Fig. 3, the dependence for the sample 2 can be characterized by considerable shift of stoichiometric equilibrium between components towards an excess of gallium atoms $\left(c_{\mathrm{Ga}}-c_{\mathrm{As}} \sim 0.047\right)$, which corresponds to a change of concentration about $10^{20} \mathrm{~cm}^{-3}$. Apparently, such change can not be caused by silicon dopant that substitutes As nodes, because its concentration in this sample is equal only to $2.5 \cdot 10^{19} \mathrm{~cm}^{-3}$ (in accordance with SIMS data). Possible shifting IR minimum, that can be caused by such amount of silicon atoms (in conditions of As nodes substitution), is close to $\sim 0.002$. Here it is important to note that in LPE method the films 


\section{V.P. Klad'ko et al.: Structural and composition irregularities in GaAs:Si/GaAs ...}

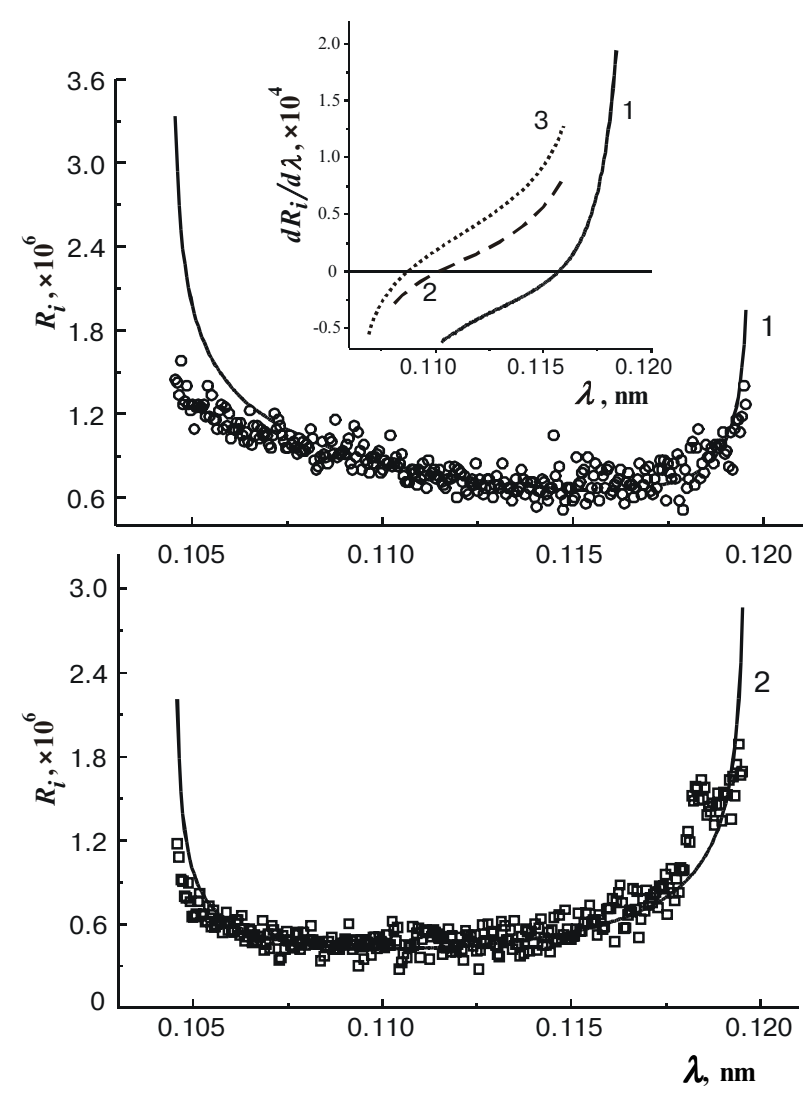

Fig. 2. IR energy dependencies for GaAs:Si/GaAs epitaxial structures: experimental dependencies (sample $\mathrm{N} 2-1$; sample $\mathrm{N} 5-2$ ). On the insertion the derivations of IR energy dependencies are shown: experimental dependencies $(1,2)$, perfect sample (simulation) (3).

grow from the melt supersaturated by gallium. It can be an additional factor of equilibrium shift towards the $\mathrm{Ga}$ excess side. The $p$-type of films conductance $\left(\mathrm{Si}_{\mathrm{As}}\right.$ is an acceptor) testifies in favor of silicon substitution of As nodes. The essential discordance between amount of dopant atoms and carriers concentration (Table 1) is possible to be explained by cluster type Coulomb type (with square-law of deformation fields changes from a defect center) structural defects formation at the cost of silicon atoms that are not electrically active.
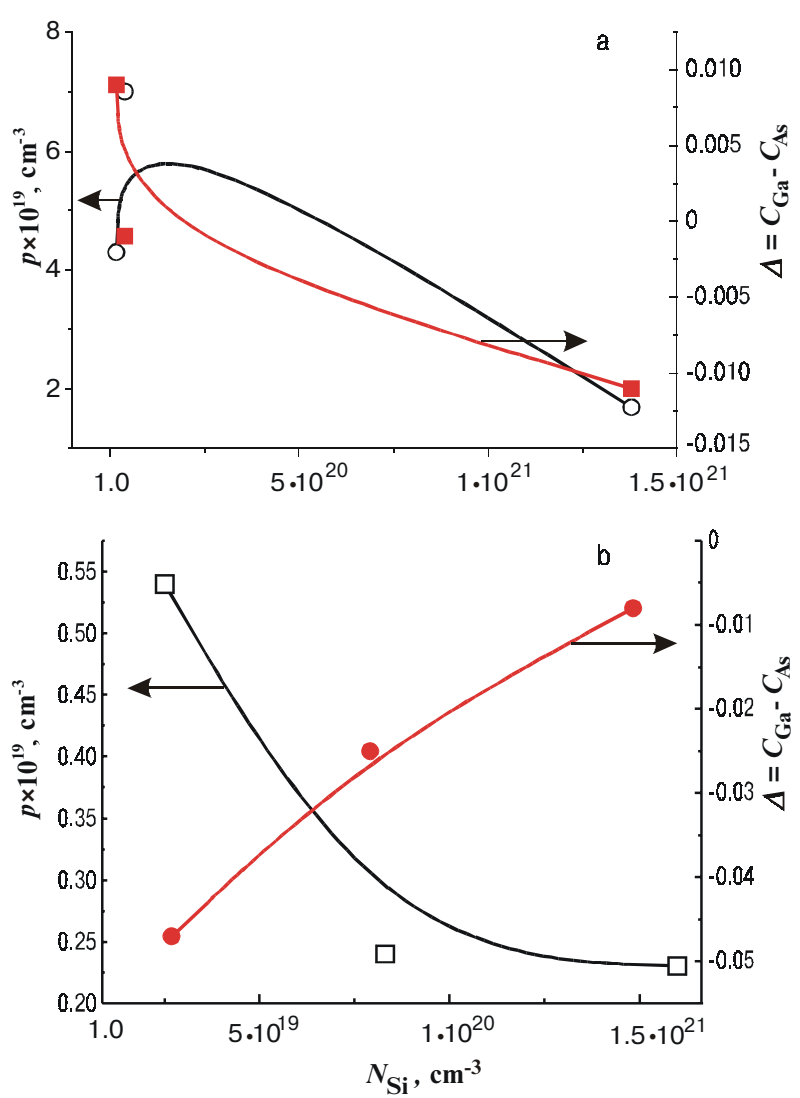

Fig. 3. Dependencies of carriers concentration and stoichiometry parameters on concentration of dopant: thin films (a), thick films (b).

The analysis of energy dependencies of sample 5 testifies that, despite major concentration of dopant $\left(N_{\mathrm{Si}}=1.6 \cdot 10^{20} \mathrm{~cm}^{-3}\right)$ relatively to sample 2 , the stoichiometry parameter slightly decreases $\left(c_{\mathrm{Ga}}-c_{\mathrm{As}} \sim 0.008\right)$. This fact could be explained by two reasons: 1) atoms of silicon are partly introduced into a gallium sublattice $\left(\mathrm{Si}_{\mathrm{Ga}}\right.$ is a donor) and compensate to some extent a $p$-type conductance; 2) filling of As sublattice with silicon atoms is decreased due to increasing concentration and sizes of Coulomb deformation centers, in formation of which this dopant takes place.

Table 1. The parameters of GaAs:Si/GaAs epitaxial structures.

\begin{tabular}{ccccc}
\hline Sample № & $\begin{array}{c}\text { Concentration of } \\
\text { Si impurities, } \mathrm{cm}^{-3} \\
\text { (SIMS) }\end{array}$ & $\begin{array}{c}\text { Concentration } \\
\text { of current } \\
\text { carriers } p, \mathrm{~cm}^{-3}\end{array}$ & $\begin{array}{c}\text { Mobility of } \\
\text { current } \\
\text { carriers, } \mathrm{cm}^{2} / \mathrm{V} \cdot \mathrm{s}\end{array}$ & $\begin{array}{c}\text { Thickness } \\
\text { of the film } \\
t, \mu \mathrm{m}\end{array}$ \\
\hline 1 & $1.6 \cdot 10^{19}$ & $4.3 \cdot 10^{19}$ & 13 & 4 \\
\hline 2 & $2.5 \cdot 10^{19}$ & $5.4 \cdot 10^{18}$ & 20 & 13.4 \\
\hline 3 & $3.9 \cdot 10^{19}$ & $6-8 \cdot 10^{19}$ & $5 \div 8$ & 7.8 \\
\hline 4 & $8.3 \cdot 10^{19}$ & $2.4 \cdot 10^{18}$ & 30 & 14.6 \\
\hline 5 & $1.6 \cdot 10^{20}$ & $2.3 \cdot 10^{18}$ & 30 & 4.3 \\
\hline \hline
\end{tabular}




\section{V.P. Klad'ko et al.: Structural and composition irregularities in GaAs:Si/GaAs ...}

The analysis of numerical processing of measurement data shows, that the concentration of clusters $n_{c l}$ (Coulomb deformation centers) in a sample 5 really increased by two orders of magnitude in comparison with the sample 2, and their sizes increased twice (Table 2). It confirms our assumption about participation of silicon atoms in microdefects formation in the sample 2. The evolution of structure factor value testifies that such microdefects can be cluster associations formed through participation of silicon atoms. Thus, the silicon atoms can be localized in tetrahedral sites of the GaAs lattice with the most close neighborhood of $\mathrm{Si}_{\mathrm{Ga}}$, placing in the planes of $\mathrm{As}$ sublattice. It is followed by a shift of four closest neighbours (As atoms) along directions to a microcluster, which reduces the lattice parameter of GaAs. Thus, Si atoms located in tetrahedral sites, which for the chosen reflections are localized in arsenic planes, reduce crystal stoichiometry degree. The array of such microclusters localized in particular volume of a sample perhaps forms a structural Coulomb center, parameters of which (e.g., concentration and size) influence on an IR value.

As follows from results of processing of energy dependencies of QFR IR measurement data, the parameter of stoichiometry depends on dopant concentration (Fig. 4). At the same time, for epilayers with thickness equal to about 5 microns, parameter of stoichiometry $D$ decreases with increasing silicon concentration in the lattice, while for structures with the greater thickness $\sim 15 \mu \mathrm{m}$ such decreasing takes place too, but from the other side (the places of silicon localization in the GaAs lattice for both cases are different). The concentration of carriers, as follows from Fig. 4, is decreased both for thick and thin samples with increasing $N_{\mathrm{Si}}$.

Such behaviour of carrier concentration could be explained by an amphoteric nature of silicon dopant. It is known that at high levels of doping the silicon occupies arsenic sites and acts as acceptor. Accordingly to saturation of As nodes by silicon with increasing $N_{\mathrm{Si}}$, the mechanism of gallium site saturation begins actively work. $\mathrm{Si}_{\mathrm{Ga}}$ is a donor, therefore compensation of $p$-type conductance and decreasing of carrier concentrations takes place. Such behavior of concentration is explained by changing stoichiometry parameter. The entrance of silicon in

Table 2. The characteristics of defects (Coulomb centers of deformation) and the value of stoichiometry parameter for GaAs:Si/GaAs epitaxial structures.

\begin{tabular}{ccccc}
\hline $\begin{array}{c}\text { Sample } \\
\text { № }\end{array}$ & $\begin{array}{c}R_{0}, \\
\mu \mathrm{m}\end{array}$ & $\begin{array}{c}n_{c l}, \\
\mathrm{~cm}^{-3}\end{array}$ & $\Delta=C_{\mathrm{Ga}}-C_{\mathrm{As}}$ & $R, \%$ \\
\hline 1 & 5 & $9 \cdot 10^{6}$ & -0.009 & 1.16 \\
\hline 2 & 1 & $2.5 \cdot 10^{6}$ & 0.047 & 2.3 \\
\hline 3 & 4.6 & $1 \cdot 10^{7}$ & 0.001 & 1.25 \\
\hline 4 & 4.9 & $5 \cdot 10^{6}$ & -0.025 & 1.29 \\
\hline 5 & 1.8 & $2 \cdot 10^{8}$ & 0.008 & 1.5 \\
\hline 6 & 3 & $6.5 \cdot 10^{6}$ & 0.011 & 1.36 \\
\hline \hline
\end{tabular}

$S Q O, 3(3), 2000$

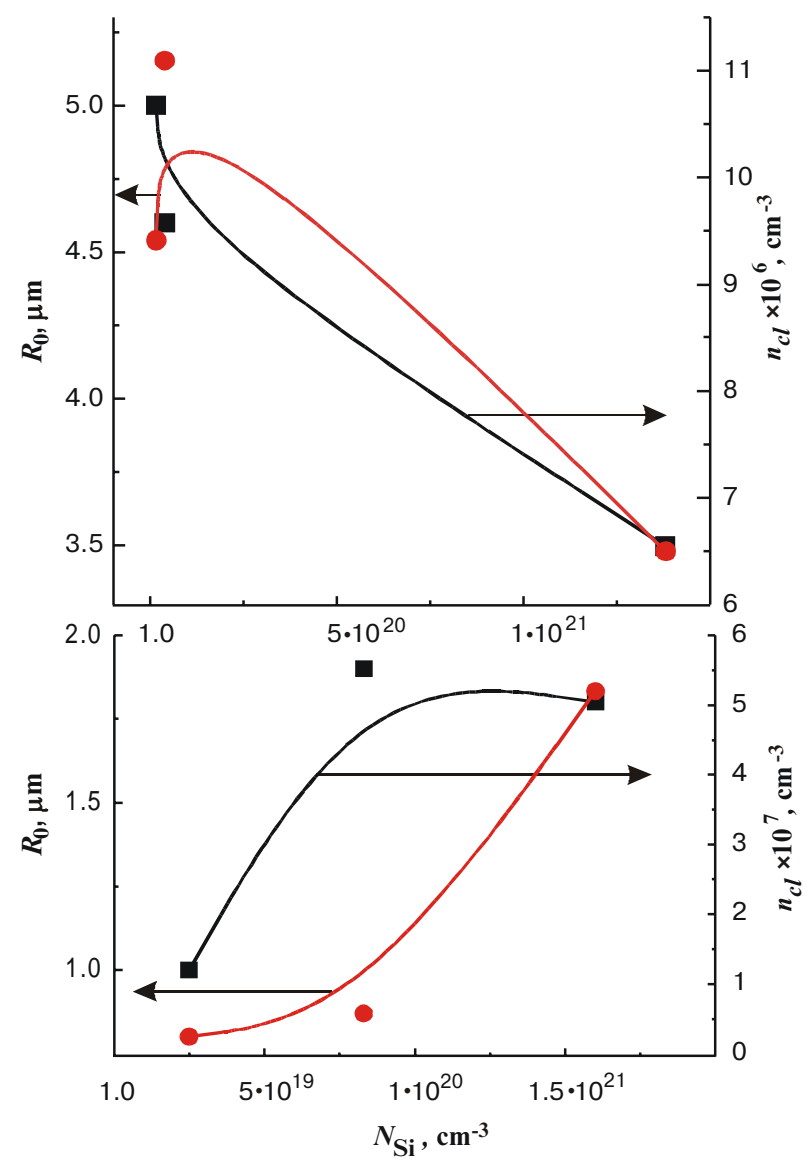

Fig. 4. Dependencies of defects parameters on dopant concentration: thin films (a), thick films (b).

gallium nodes leads to decreasing of stoichiometry parameter for thick films, and the entrance of silicon into places of gallium vacancies for thin films leads to decreasing $p_{0}$, which cause decreasing value of $\Delta$.

It is possible to explain the behavior of characteristic sizes of microdefects in thin films (decreasing of $R_{0}$ with increasing $N_{\mathrm{Si}}$ ) and in thick films (increasing of $R_{0}$ with increasing $N_{\mathrm{Si}}$ ) by film thickness restriction of their characteristic sizes. In thick film, where saturation is reached when filling sublattice sites by silicon atoms, there appears increasing of the microdefects effective sizes. In thin films, the maximum radii of microdefects is restricted by the film thickness. With increasing $N_{\mathrm{Si}}$ the concentration of microdefects increases, leading to overlapping microdefects deformation fields, that is equal to their effective sizes decreasing.

Among these experimental results, it is important to note a satisfactory correlation in behaviour of carriers mobility and sizes of microdefects. It is clear that there takes place active scattering of carriers on microdefects (silicon precipitates).

In Table 3, data of IR measurements for a characteristic irradiation line and radii of curvature of systems film-substrate are shown. The analysis of results shows, that the doping of films by silicon leads to changing a sign of system deformation, that is from concave (undoped sample №0) to convex from the film side for others sam- 


\section{V.P. Klad'ko et al.: Structural and composition irregularities in GaAs:Si/GaAs ...}

Table 3. The integrated intensities of characteristic irradiation for reflections (200), (400), (600) and elastic strains in epitaxial layers.

\begin{tabular}{cccccc}
\hline \hline Sample № & $R_{i}^{200} \times 10^{6}$ & $R_{i}^{600} \times 10^{7}$ & $R_{i}^{400} \times 10^{5}$ & Curvature & $\begin{array}{c}\text { Strain, } \\
\text { radius, } \mathrm{m}\end{array}$ \\
\hline 0 & 1.44 & 4.92 & 4.11 & -67.94 & -1.99 \\
\hline 3 & 1.34 & 5.27 & 5.02 & 56.72 & 4.21 \\
\hline 6 & 1.42 & 5.54 & 5.33 & 24.54 & 15.71 \\
\hline \hline
\end{tabular}

ples. The lattice tension is caused by the fact that tetrahedral covalent radius of silicon $r_{\mathrm{Si}}=1.17 \AA$ is more, than $\mathrm{Ga}$ or As. The estimation of average concentration of silicon in film, which could lead to such strains, clarifies that it is less than given by the SIMS method. This fact also confirms that the part of silicon atoms takes part in precipitate formation. Values of QFR IR of (200) and (600) reflections completely correlate with values for (400) reflections, which is sensible to residual strains of crystal (intensity increased with strain increasing). This fact shows that applications of these data for stoichiometry parameter control must be done with some caution.

\section{Conclusions}

The analysis of changes in energy dependence of QFR IR for epitaxial films grown by LPE method shown that value of stoichiometry parameter depends on their structural perfection (Coulomb deformation centers enriched with silicon presence in films). Therefore, the doping level of crystals (epitaxial layers) by silicon atoms, which is determined by SIMS method can not always correlate with concentration of major carriers. It depends on number of silicon atoms that substitute atoms of native components of a crystal. The data which argue that the size and concentration of the Coulomb centers depends on thickness of epitaxial layer limiting the «size» of silicon precipitates were obtained, too.

\section{References}

1. M. Lannoo, J. Bourgoin. Points defects in Semiconductors I / / Berlin: Springer Verlag, 263 p. (1981).

2. K. Terashima, J. Nishio, A. Okada, S. Washizuna, M. Watanabe. Stoichiometry of undoped LEC GaAs // J. Cryst. Growth, 79, pp.463-468(1986).

3. N.F. Chen, H. He, Y.Wang, L. Lin. Stoichiometryc defects in semi-insulating GaAs // J. Cryst. Growth, 173, pp. 325-329 (1997).

4. L.A. Charniy, A.N. Morozov, V.T. Bublik, K.D. Scherbachev, I.L. Stepantsova, V.M. Kaganer. Study of microdefects and their distribution in dislocation-free Si-doped HB GaAs by $\mathrm{X}$-ray diffuse scattering on triple-crystal diffractometer // $J$. Cryst. Growth, 118, pp. 163-175 (1992).

5. G. Frigerio, C. Mucchino, J.L. Weyhev L., Zanotti, C. Paorici. Dislocations and microdefects in $L E C$-grown silicon-doped gallium arsenide crystals // J. Cryst. Growth, 99, pp. 685-691 (1990).
6. I. Fujimoto. Structural aspects of non-stoichiometry and heavy doping of GaAs // Materials Science and Engineering, B14, pp. 426-438 (1992).

7. I. Fujimoto. Characterisation of stoichiometry in GaAs by XRay intensity measurements of quasi-forbidden reflections // Jap. J. Appl. Phys., 23(5), pp. L287-L289 (1984).

8. L.I. Datsenko, V.P. Klad'ko, V.M. Mel'nik, V.F. Machulin. Osobennosti tolshchinnyh oscilliacij intensivnosti pri rasseianii rentgenovskih luchej vblizi K-kraia pogloshcheniia galliia dlia kvazizapreshchennyh otrazhenij // Metallofizika $i$ novejshie tehnologii, 21(8), pp. $46-54$ (1999).

9. V.P. Klad'ko, L.I. Datsenko, V.F. Machulin. Vplyv defektiv struktury v GaAs na harakter laye-dyfrakcii rentgenivs'kyh promeniv z dovzhynamy hvyl', blyz'kymy do K-kraiv poglynannia atomiv pidgratok // Ukrains'kyi fizichnyi zhurnal, 44(9), pp. 1148-1154 (1999).

10. V.G. Bar'iahtar, A.N. Gureev, V.V. Kochelab, V.B. Molodkin, S.I. Olihovskij, M.E. Osinovskij. Polnoe integral'noe breggotrazhenie rentgenovskih luchej i opredelenie strukturnogo sovershenstva real'nyh monokristallov // Metallofizika, 11(3), pp. 73-81 (1989).

11. V.B. Molodkin, S.I. Olihovskij, E.N. Kislovskij, V.P. Krivickij, A.V. Los', E.V. Pervak, Dzh.E. Ajs, B.K. Larson Interpretaciia krivyh otrazheniia monokristallov s mikrodefektami v sluchae dinamicheskoj difrakcii rentgenovskih luchej po Breggu // Metallofizika i novejshie tehnologii, 19(12), pp. 25-34 (1997).

12. V.P. Klad'ko, L.I. Datsenko L.I., S.J. Olihovs'kij S.J., V.F. Machulin, I.V. Prokopenko. Analiz nestehiometrii i harakterystyk mukrodefektiv pry dyfrakcii rentgenivs'kih promeniv po Bregu // Naukovij visnyk Chernivets'kogo universitetu. Fizyka. Elektronika, 6, pp. 28-38 (1999).

13. P.H. Dederichs. Diffuse scattering from defect clusters near Bragg reflections // Phys. Rev(b)., 4(1), pp. 1041-1050 (1971).

14. E. Brugren, O. Efimov, E. Person. Opredelenie effektivnoj velichiny «spektral'nogo okna» rentgenovskogo kristall spektrometra. // Fizika tviordogo tela, 10(9), pp. 2716-2723 (1968).

15. T. Fukamachi, S. Hosoya, T. Kawamura, M. Okunuko. $X$ Ray Intensity Measurements on Large Crystals by EnergyDispersive Diffractometry. Preprint of the Institute for Sol. Stat. Phys. the University of Tokyo. Tokyo. N760. 20p. (1976)

16. D.T. Cromer. Anomalous dispersion corrections computed from self-consistent field relativistic Dirac-Slater wave function // Acta Cryst., 18, pp. 17-23 (1965).

17. U. Pietsch. X-ray structure amplitudes for GaAs and InP // Phys. Stat. Sol.(A), 87, pp. 151-156 (1985).

18. H.M. Rietveld. A profile refinement method for nuclear and magnetic structures // J. Appl. Cryst., 2(2), pp. 65-72 (1969).

19. A.N. Baranov, T.I. Voronina, T.S. Lagunova, M.A. Sipovskaia, V.V. Sherstnev, Yu.P. Iakovlev. Svojstva epitaksial'nogo arsenida indiia, legirovannogo redkozemel'nymi elementami // Fizika $i$ tehnika poluprovodnikov, 27(2), pp. 421-429 (1993).

20. Yu.A. Thorik, L.S. Hazan. Plasticheskaia deformaciia $i$ dislokacii nesootvetstviia $v$ geteroepitaksial'nyh sistemah. Kiev, Naukova dumka, 304 p. (1983). 